\title{
STUDY ON THE FUNCTION OF THE BIOFILM ATTACHED TO MEMBRANE ON EFFLUENT QUALITY IN MBR
}

\author{
Yanhong Xu \\ Beihua University, China
}

\begin{abstract}
Combined membrane separation processes with biological treatment technology; membrane bioreactor (MBR) is a new efficient wastewater treatment technique for the advantage of high removal rate, high quality effluent and stable treatment effect etc. However, being conventionally identified that the removals of contaminants is dependent on suspended growth-activated sludge system and micro porous membranes in the MBR. In this paper, a Laboratory MBR using a submerged polyethylene hollow-fribre membrane module with a pore size of $0.45 \mathrm{~nm}$ and a total surface area of $0.1 \mathrm{~m}$ was used for treating raw water from artificial water. The actual operation indicated that membrane separation achieved to not only solid-liquid in the intermixture, but also the separation of soluble organics from water. A comparison of the effluents between a new film and an old film was carried out under soluble microbial product (SMP) accumulated in MBR. Experiment result shows that the effluent quality of the old film is more stable and excellent than the new film. The feeding influent had a total organic carbon (TOC) level of $437 \mathrm{mg} / \mathrm{L}$. The effluent TOC concentration of the old film is $12.9 \mathrm{mg} / \mathrm{L}$, on average, much lower than the new film $(36.9 \mathrm{mg} / \mathrm{L})$, which indicates the intensified interception of SMP by the biofilm attached membrane. In the MBR supernatant, both macromolecules with molecular weight (MW) $>10 \mathrm{ku}$ and small molecules with $\mathrm{MW}<3 \mathrm{ku}$ are dominant and have a much larger occupation. The old film interception for all molecules with different MW is more effective than the new film. After the cleaning of the old film, with the falling of membrane specific flux, its effluent TOC concentration will decline. These results indicate that the biofilm attached to membrane in the MBR could obtain the separation of soluble organics from water, consequently improve the quality of the effluent.
\end{abstract}

\section{INTRODUCTION}

As an efficient and economical waste water treatment system, membrane bioreactor (MBR) is a combination of membrane separation processes with biological treatment technology. Because of its high efficiency, good water purification, water quality and stability characteristics, MBR is paid more extensive attention to all over the world. However, being conventionally identified that the removals of contaminants is dependent on suspended growth-activated sludge system and micro porous membranes in the MBR[1], the actual operation showed that the membrane separation achieved not only the solid-liquid separation from the activated sludge mixture, but also realized the separation of dissolved organic matter from water[2]. Relying solely on the role of membrane physical interception clearly can not achieve the separation of dissolved organics from water, so the biofilm of the membrane surface took the two stesps separation task. Visvanathan $\mathrm{C}$, etc., compared the effluent from micro filtration membrane and nanofiltration membrane applicated respectively in MBR, 
effluent quality having little difference, proved that the biofilm attached to the membrane surface plays an important role in stabilizing the effluent [3].

For the high sludge concentration, during the operation it need to strengthen the transfer process to enhance bio-degradation effect, therefore the contact with microorganisms and the membrane surface also has been strengthened, making it easy for bacteria stick to the membrane surface form biofilm. Biofilm formation limited the membrane flux, and caused to membrane fouling[4].Biological pollution will make membrane flux decline directly, and increase energy consumption in the MBR. Thus how to avoid or reduce the biological contamination became the hotspot of studying on MBR. As the membrane contacts with the mixture of sludge in the reactor directly, forming the biofilm attached to the surface of the membrane is inevitable[5] . Reported in some literature ,the surface of the membrane biofilm made flux decline, but also strengthened the quality of effluent [6,7] but none of these essays discussed on the subject thoroughly.In view of the complexity of MBR process for the contaminants removal and studying on the removing contaminants mechanism, it's neccesary to confirm the enhancement of biofilm attached to membrane on effluent quality.

\section{MATERIAL AND METHODS}

\subsection{Experimental set-up}

Seed activated sludge was took from water treatment plant in Beihua University and placed in the MBR, before the system was operated continuously, the sludge had been acclimated intermittently for 15 days.

A submerged MBR was used in the experimental study. Reactor had an effective volume of $10 \mathrm{~L}$, there is a hollow fiber membrane modules inside the reactor,which was made of polyvinylidene fluoride (PVDF), a pore size of $0.1 \mu \mathrm{m}$ and a total surface area of $1.0 \mathrm{~m}^{2}$,was immersed inside an activated sludge system. Experimental process is shown in Fig. 1, feeding water tank, balance tank, a lever controller was used to regulate by a float valve, while the effluent was drawn from from the MBR through the membrane by a peristaltic pump with constant current mode, flow controlled in $2 \mathrm{~L} / \mathrm{h}$. A vacuum meter was mounted between the membrane module and the peristaltic pump to monitor the transmembrane pressure(TMP). During the stable operation, the time of the peristaltic pumb working and stopping was $12 \mathrm{~min}$ and 3 min, sludge retention time(SRT) was 40 days. And the membrane modules being immersed in the running reactor with activated sludge mixture, a layer of biofilm adhered to the membrane surface, called the old film.To compare with the effluent through the old film, the bundle membrane with the same material and aperture was used as a sample membrane, membrane filtration area of $0.1 \mathrm{~m}^{2}$, called the new film. The new film was immersed in the reactor, after getting $200 \mathrm{~mL}$ water, we set sample each time. In order to prevent the membran from biological contamination, the new film was removed and cleaned once by water flusing after sampling, and chemical backwash with $\mathrm{NaOCl}\left(1.5 \%\right.$ free $\left.\mathrm{Cl}_{2}\right)$ was performed for $2 \mathrm{~h}$ approximately, then soaked the membrane in water for later use. 


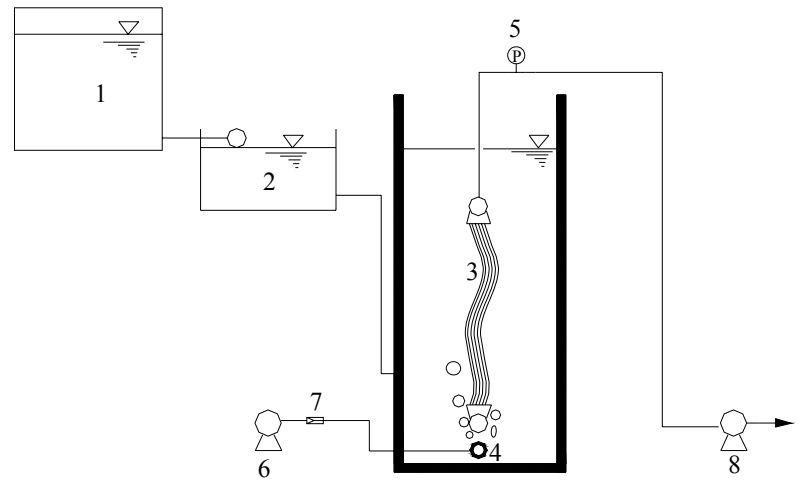

Fig.1 Diagrams of MBR

1.feeding influnet tank; 2. balance tank; 3. membrane module 4. perforated pipe 5. vacuum meter 6. aeration pump 7. gas flow meter 8. peristaltic pump

\subsection{Influent water samples}

Influent water was used for the artificial water to simulate the concentration of domestic wastewater, whose composition shown in Table 1.

Table 1 Organic components and concentration of artificial compounded water $(\mathrm{mg} / \mathrm{L})$

\begin{tabular}{cc|cc}
\hline components & concentration & components & concentration \\
\hline Glucose & 169 & $\mathrm{KH}_{2} \mathrm{PO}_{4}$ & 44 \\
Peptone & 169 & $\mathrm{CaCl}_{2}$ & 23.3 \\
$\mathrm{NaHCO}_{3}$ & 94 & $\mathrm{MgSO}_{4} \cdot 7 \mathrm{H}_{2} \mathrm{O}$ & 94 \\
$\mathrm{NaCl}$ & 63 & $\left(\mathrm{NH}_{4}\right)_{2} \mathrm{SO}_{4}$ & 63 \\
$\mathrm{FeSO}_{4} \cdot 2 \mathrm{H}_{2} \mathrm{O}$ & 2.2 & & \\
\hline
\end{tabular}

The average water quality COD $437 \mathrm{mg} / \mathrm{L} \quad B_{0} O D_{5}=217 \mathrm{mg} / \mathrm{L}$

\subsection{Analytical methods}

Conventional analysis projects: TOC of the influent water, supernatant in the MBR and the effluent, were determined using standard methods[8]. The supernatant in the MBR was centrifugated under $3000 \mathrm{r} / \mathrm{min}$ for $10 \mathrm{~min}$, and was filtered through $0.45 \mu \mathrm{m}$ membrane. TOC was measured by a TOC analyser(TOC ) based on the combustion-infrared method were determined after membrane filtration.

Determination of molecular weight distribution [9]: quantitative sample was taken and filtered through $0.45 \mu \mathrm{m}$ of the membrane, then using different molecular weight cut membrane $(1000,3000,4000,10000,30000)$ filter, TOC of the filtrate was determined.By the material balance, the different molecular weight ratio of the total organic matter can be caculated.

\section{RESULTS AND DISCUSSION}

\subsection{SMP interception effect}


Interception efficiency of the membrane in the MBR could improve water quality, at the same time, the reactor also formed a relatively closed system [10]. Soluble microbial products (SMP) formed from the process of microbial decompositing organic matter will be in response accumulated inside. SMP is the main components soluble TOC and COD in the biologically treated water, its composition is very complicated, which is a mixture of humic acid, polysaccharides, proteins, nucleic acids, organic acids, antibiotics and other substances , containing a large number of polymer material[11]. During the experimental period,influent water contained easily biodegradable organic matter, while some part of the organic could have enough residence time in the reactor, so TOC of the supernatant in the reactor can be considered as microorganisms of the SMP.

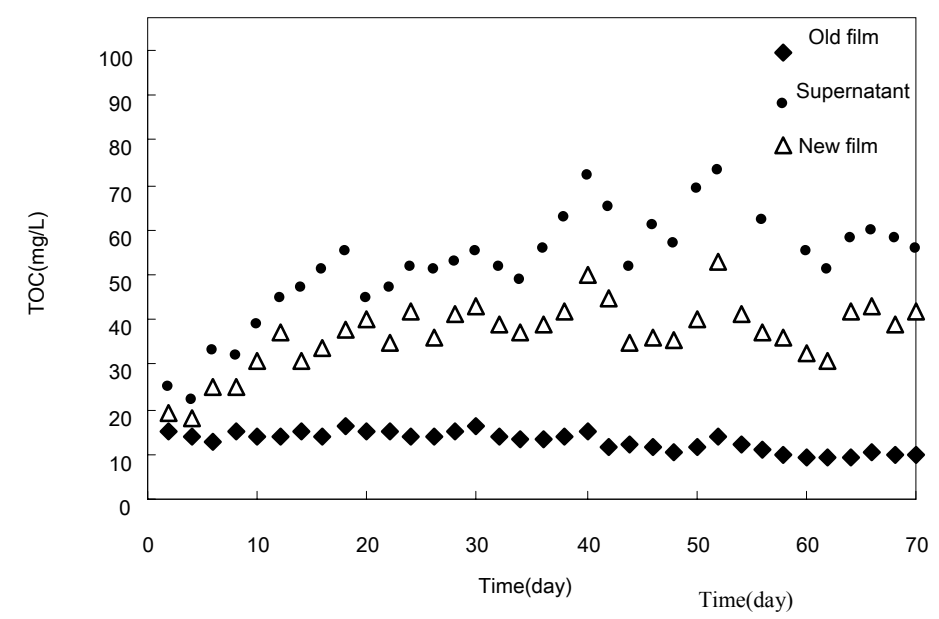

Fig 2 Comparisons of the SMP concentration and effluent TOC concentration though membrane

Fig. 2 shows SMP and TOC concentration of the two membrane in the reactorr. Being seen from Fig.2, during the experiental period of 70 days, the SMP accumulation occurred inside the the reactor. In the Initial stage, concentration of SMP was $21 \mathrm{mg} / \mathrm{L}$. After 10 days, the SMP concentration had the level of $45 \sim 73 \mathrm{mg} / \mathrm{L}$ in MBR. During the entire operation, the effluent had a TOC removal rate more than $90 \%$, indicating membrane system has a strong stabilizing effect. Effluent from the new film, its SMP concentration was effectted by the water quality inside reactor, with the SMP concentration in the reactor increased, and the effluent TOC level of $19 \sim 43 \mathrm{mg} / \mathrm{L}$ volatility, the average effluent TOC concentration of $36.8 \mathrm{mg} / \mathrm{L}$, which shows that the SMP rejected have serious limitations only by the physical rejection and adsorption of the membrane. The effluent through the old film had a TOC level of $9 \sim 16 \mathrm{mg} / \mathrm{L}$, while the reactor is running in later stage, SMP had a great number of accumulation, but the water has been more stable, effluent quality was not effectted obviously by the SMP concentration, the average effluent TOC concentration to $12.9 \mathrm{mg} / \mathrm{L}$, which shows the biofilm of the membrane surface plays an important role in rejection by its second rejection and adsorption on the SMP, the system is always maintained on the removal of organic matter at a high level. Chang IS [12] and other tests on the conventional activated sludge ultrafiltration, also Concluded that the dissolved organic matter was removed mainly by the sediment layer of the membrane surface. 




Fig. 3 The rate of interception comparisons between membrane itself and biofilm

Fig. 3 compares the retention rate of SMP of the membrane itself and the biofilm on the surface of membrane, the biological rejection rate was caculated by the difference between the old film biofilm and rejection of the new film,that directly displays the SMP retention contributions of biofilm. Being seen from Fig. 3, the rejection rate of the biofilm on the SMP increases overtime significantly, the retention rate of $18.8 \%$ in the early stage was up to $58.6 \% 62$ th day. Relatively, the retention rate of the membrane will not significantly increase.

During the MBR operation, due to the shear force of the aeration, not only the diameter of sludge particles has been decreased, and it will stimulate the extracellular polymeric substances (EPS) release [13]. EPS is a sticky substance secreted by microbial cells which is an important component of biofilm formation material. EPS and the membrane can penetrate each other,and EPS can be linked closely with the membrane by chemical bonds to change the water permeability and permeability of the membrane [14], to improve the retention capacity of SMP. With the system operation, biofilm achieved the dynamic balance of growth and falling gradually to ensure the surface membrane biofilm retention on the stability of SMP. The biological rejection of the biofilm has not only enhanced the the effluent quality,but also has prolonged the hydraulic retention tine(HRT) of big molecule and non-degradation organic compound in reactor, and strengthened the removal rate of the system on these nondegradation organic matter.

\subsection{The SMP composition of organic matter in the reactor and effluent}

As the SMP composition is complicated, its chemical composition is still not identified across the board and accurately. The author adoptted cutting methods to characterize the molecular weight distribution of SMP in the reacto. According to the specification of the membrane, the molecular weight distribution is divided into six intervals during the SMP research. 


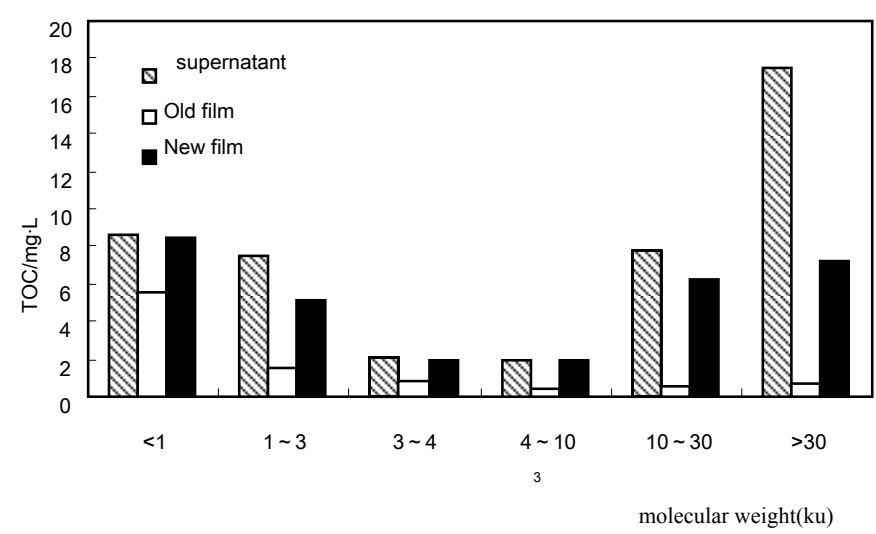

Fig.4 Molecular weight distribution of SMP in the reactor and effluent

Fig. 4 reflects the molecular weight distribution working of the six intervals in the MBR supernatant and effluent. From Fig. 4, MBR supernatant has bimodal molecular weight distribution characteristics, most of the material molecular weight is greater than 10,000 or less than 3,000, which organic matter more than 10000 accounts for $55 \%$, and less than 3000 accounts for $35 \%$. Sum of both parts TOC accounts for $90 \%$ of total concentration. The organic molecular weight distribution of the effluent from new film is similar to the MBR supernatant, showed bimodal characteristics, distributing widely. The organic molecular weight distribution of the effluent from old film being smaller than 3000's minor numerators mainly, accounts for $72.9 \%$ of the effluent TOC.

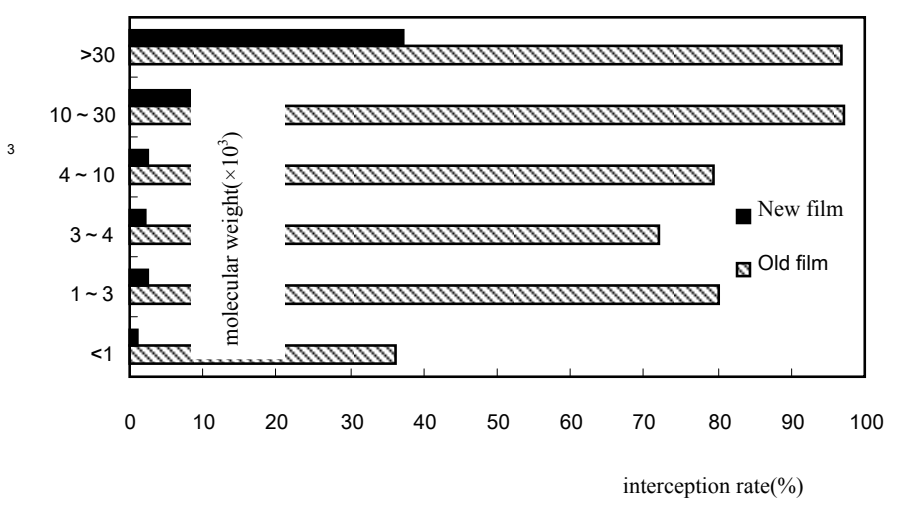

Fig.5 The interception rate of SMP distribution

The interception rate of the membrane on SMP is a ratio of the effluent SMP concentration in every interval and SMP in reactor.Films on the rejection of the interval is in the range of concentration of endometrial water reactor SMP SMP concentration ratio, Fig. 5 reflects interception rate of the new film and the old film in the six retention interval.Seen from Fig. 5, the rejection of the new film on the SMP concentrated in the organic molecular weight is greater than 10,000, more than 30000 of the SMP on $t$ was $37.4 \%, 10000 \sim 30000$ retention interval was $20.5 \%$, Other interval has low retention.For old film, the rejection rate of the molecular weight of greater than 10000 is more than 97\%.In range of 1000 to 10000 three intervals the retention rate all is greater than $70 \%$, for less than 1000 molecular weight the retention rate of organic molecule is $36 \%$. All above has finally indicated that biofilm 
formation of membrane surface is almost completely retained the SMP of macromolecules, and small organic molecules have significant retention capacity, having a crucial role in the stabile effluent.

\subsection{The relationship of membrane specific flux and the SMP in the effluent}

Membrane specific flux(MSF) is expressed the flux of membrane filtration under unit pressure. membrane filtration is often used to characterize the process of membrane pollution and changes in membrane filtration performance, with $\mathrm{J} / \mathrm{P}$ value indicates. The biofilm formation of the membrane surface will directly affect the membrane specific flux, so the change of the membrane specific flux can indirectly reflect the membrane filtration properties of the biofilm attached to membrane surface.



Fig.6 Change of effluent TOC concentration and membrane specific flux

Until the test had run for 70days, the old film was cleaned to remove the biofilm attached to the surface of the hollow fibre membrane. With the falling of membrane specific flux, its effluent TOC concentration will decline. Fig. 6 reflects the film by washing, the membrane specific flux and the effluent TOC changed with the running time. Fig. 6 shows that, in the 12 hours, the membrane specific flux decreased rapidly, then slowly decreased and stabilized, indicating that the membrane surface biofilm formation occurred at the beginning of filtration, and it completed basically in a short period of time .The effluent TOC decrease with the membrane specific flux decline, after $1 \mathrm{~h}$ running effluent TOC was $32 \mathrm{mg} / \mathrm{L}$, after $48 \mathrm{~h}$ running, the effluent TOC became stable at $12 \pm 2 \mathrm{mg} / \mathrm{L}$.

This shows the rapid formation of biofilm made effluent stable. In the initial stage, because of the less biological membranes, membrane filtration process relied heavily on the physical interception, and thus the effluent TOC was higher. With the membrane surface biofilm forming gradually, especially the dense biofilm formed, effluent TOC decreased and got stable correspondingly, the basic filtration process relied on the biofilm of the membrane surface . 


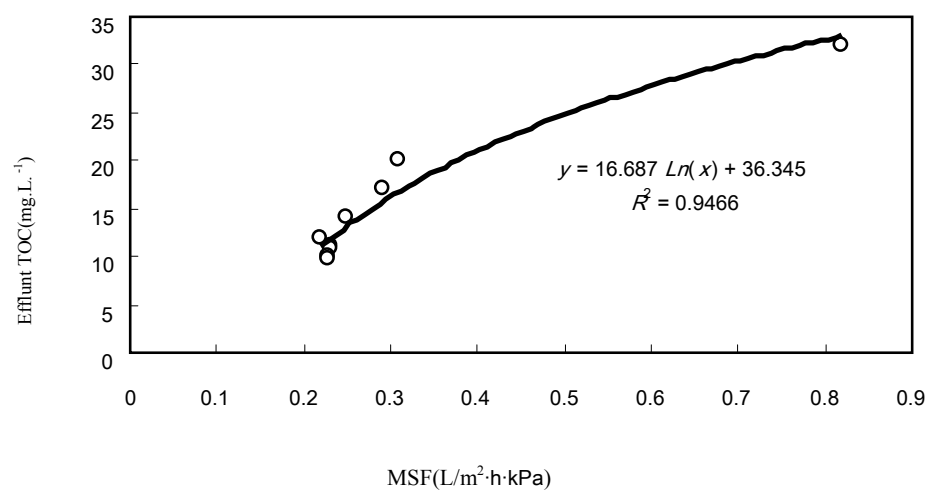

Fig.7 Relationship between effluent TOC concentration and membrane specific flux

The above analysis can be drawn, MBR process operates first, filtration process was completed their separation mainly by the membrane. With the running time, this filtering process gradually was replaced by the biofilm attached to membrane surface. When the effluent was depend on the physical retention by the membrane itself, it showed the higher concentrations of effluent TOC and unstable. When the effluent was controlled by the biofilm attached membrane surface filtration, the effluent TOC concentration was low and stable, thus in the initial period the effluent TOC concentration was closely related to the biofilm formation. Fig. 7 reflects the initial stage the relationship between the effluent TOC concentration and membrane specific flux .The curves can be seen from the figure, the membrane specific flux and effluent TOC had a good logarithmic relationship, by equation (1):

$$
y=16.687 \ln (x)+36.345
$$

in which $x$ is the membrane specific flux $\mathrm{L} / \mathrm{m}^{2} \cdot \mathrm{h} \cdot \mathrm{kappa}, y$ is effluent TOC $\mathrm{mg} / \mathrm{L}$.

\section{CONCLUSIONS}

(1)The effluent quality from new film was affected greatly by the concentration of SMP in reactor. With the increasing concentration in the SMP, the effluent TOC was high and unstable. The average effluent TOC concentration was $36.8 \mathrm{mg} / \mathrm{L}$. The effluent TOC from old film was low and stable, which is not obviously affected by SMP, the average effluent TOC concentration was $12.9 \mathrm{mg} / \mathrm{L}$. The biofilm rejection rate of the membrane surface to the SMP increased significantly with the running time.

(2) The organic molecular weight distribution of MBR supernatant has bimodal characteristics, the $90 \%$ material molecular weight was greater than 10000 or less 3000 . The new film had interception effect on the molecular weight of greater than 10000 organic molecules, retention rate of $37.4 \%$ on more than 30000 organic molecular, retention rate of $20.5 \%$ on $10000 \sim 30000$, on less than 10000 organic molecules had no significant interception. The old films had the interception of large organic molecules at $97 \%$ on molecular weight greater than 10 000, for organic molecules molecular weight less than 1000 retention rate was $36 \%$.

(3)After the old film being cleaned, the effluent TOC reduced with the flux of membrane decreased, The relationship between the initial flux of membrane and the effluent TOC is $\mathrm{y}=$ $16.687 \ln (\mathrm{x})+36.345$. 


\section{REFERENCES}

[1] Chen Wei-ping,Gu Ping,Liu Jin-xia.(2003)Removal law of different molecular weight in membrane bioreactors.China Water \& Wastewater, 19(2):43 45.

[2] He Yi-liang, Gu Guo-wei.(2001) mathematical model of tow steps separation in membrane bioreactors. China Water \& Wastewater, 17(2):22 24.

[3] Visvanathan C, Aim R B, Parameshwaran K. Membrane separation bioreactor for wastewater treatment[J].Crit Rev Environ Sci. Technol.,2000,30(1):1 48.

[4]Gu Guo-wei,He Yi-liang. Study and application of membrane bioreactors(MBR) to wastewater treatment[M].Beijing: Chemical Industry Press,2002,298 299.

[5] Nagaoka H, Ueda S, Miya A. Influence of Bacterial Extracellular Polymers On the Membrane Separation Activated Sludge Process[J]. Wat Sci Tech, 1996, 34(9): 165 172.

[6] ZHANG Ying, REN Nan-qi, WU Yi-ning, DU Chang-jie. Intensified removal of organic contaminant by membrane itself in submerged membrane bio-reactor. Journal of Harbin Institute of Technology, 2004,36(2):147 149.

[7] Xiao-yan Li, Hiu Ping Chun. (2003)Membrane bioreactor for the drinking water treatment of polluted surface water supplies[J].Water research, 2003, 37:4781 4791.

[8] Chinese National Environmental Protection Agency. Analysis method of water and wastwater[M]. (Third Edition) Beijing: Environmental Science Press,China, 1989. 362 368.

[9] Josepha M, Menabern R. Organic groups and molecular weight distribution in tertiary effluents and renovated waters[J]. Water research, 1982, 116: 399 403.

[10] Jin Ruo-fei,Zhou Ji-ti,Wang Jing.(2004) Biological characters of membrane bioreactor[J]. Microbiology China, 31(2): 121 125.

[11] Liu Rui Huang Xia Fan Bin Fijimoto Mayumi Qian Yi .Progress of studies on soluble microbial products in a membrane bioreactor[J]. Technigues and Equipment For Enviro.poll.cont.2002,3(1):1 7

[12] Chang I S, Lee C H. Membrane filtration characteristics in membrane coupled active sludge system-the effect of physiological states of activated sludge on membrane fouling[J]. Desalination, 1998, 120(3): 221223.

[13] Zhang B, Yamamoto K, et al. Floc size distribution and bacterial activities in membrane separation activated sludge processes for small scale wastewater treatment/reclamation[J].Wat.Sci.Tech.,1997,35(6):37 44.

[14] Xu Jian, Xu Zhen-liang.(2002) Progress in membrane biofouling research in wastewater membrane bioreactor. Technology of Water Treatment, 28(3):125 128. 